Research, part of a Special Feature on Landscape Scenarios and Multifunctionality - Making Land Use Assessment Operational

\title{
Generic Regional Development Strategies from Local Stakeholders' Scenarios - an Alpine Village Experience
}

\author{
$\underline{\text { Wolfgang Loibl }}^{1}$ and Ariane Walz ${ }^{2,3}$
}

\begin{abstract}
The article discusses the participatory elaboration of strategies for sustainable regional development in an Alpine tourist region in Austria to cope with global change effects evolving locally, considering climate change, economic change as well as (local) societal change. Local stakeholders in an Alpine village in the Montafon region contributed in workshops to achieve the final results: participant teams conducted system analyses of the regional system to explore key elements of the region. Narrative scenarios described possible positive and negative development trends and indicated the critical issues controlling future development; 3D-images of landscape transition simulations show the consequences of certain development directions. Alternative development directions supported the local stakeholders to elaborate regional development strategies. In the end, the scientist team derived generic strategies for Alpine regions based on the locally developed strategy bundle. The article presents the intention, progress and outcome of the participatory approach and elaborates the potential to derive generic strategies from local ones and discusses the possibly occurring conflicts regarding cross-scale transfers of these local strategies. Overall, tourism was seen as a key element for future regional development, which can on the one hand derogate Alpine regions and is on the other hand threatened by climate change and diminution of landscape attractiveness. The suggested development strategies will help to cope with global change issues mitigating the negative consequences on the local society and environment.
\end{abstract}

Key Words: alpine regions development, participatory scenario approach, regional development, generic strategies

\section{INTRODUCTION}

Global change, comprising economic, societal and climate change, will have a significant, and as yet uncertain, effect on natural and social systems. Developing exploratory scenarios (c.f. van Notten et al. 2003) help to understand these future uncertainties and to develop adaptation strategies. The experiences and expectations of local actors are integrated through a participatory process, which allows locally grounded systemic frameworks to go beyond ideas to more general strategies. Regional case studies are often the foundation of sustainability research (Scholz and Tietje 2002). Tötzer et al. (2007) or Lundström et al. (2007) are good examples of this type of work.
Sustainability has become an everyday term, encompassing both everyday and complex meanings. However, both ways of using the term refer to the Brundtland Commission's characterization (Brundtland and WCED 1987), to "meet the needs of the present without compromising the ability of future generations to meet their own needs." Poverty, hunger and the support of the underdeveloped South have been major drivers in passing the Brundtland resolution. The natural environment was understood as a resource for future generations. Despite its importance, the environmental perspective has a relatively weak position compared to the economic and society perspectives. Our belief is that local sustainable-development strategies should promote economic and social progress while preserving the environment that should not be seen

\footnotetext{
${ }^{1}$ Austrian Institute of Technology, Department Foresight and Policy Development, Regional and Infrastrucure Policy Unit, ${ }^{2}$ Potsdam Institute for Climate Impact Research (PIK), ${ }^{3}$ WSL Institute for Snow and Avalanche Research SLF
} 
just as a resource and service provider but rather as a treasure of biodiversity and beauty.

The concept of transdisciplinary research demands close collaboration between scientists and stakeholders to identify solutions for urgent problems. Sustainability research should therefore regularly include the participation of relevant actors (Klein et al. 2001, Loibl 2002, Scholz et al. 2005). The development of possible scenarios is one of the common approaches used in such collaborations between scientists and stakeholders (e.g., Loukopoulos and Scholz 2004, Walz et al. 2007).

In this paper, we refer to a case study developed in Loibl et al. (2008a). This particular case is interesting for several reasons. First, the methods can be easily applied to related questions. Second, the results can help to understand the dynamics of regions with similar physical and social characteristics. Finally, the strategies developed locally could be applied for sustainable regional development on a more general basis.

\section{The case study region "Montafon"}

The Montafon region is located in the western Austrian Alps, bordering Switzerland. The area addressed in the case study comprises six municipalities in the valley of the Ill River, an affluent of the Upper Rhine, south of Lake Constance. The area comprises around $250 \mathrm{~km} 2$, with about 12,000 inhabitants (2001). The main settlements are situated on the valley floor, with an average altitude of $650 \mathrm{~m}$. The surrounding mountains reach elevations up to $3300 \mathrm{~m}$. The population in the valley has grown slightly in recent decades. The number of households has increased from 3200 (1981) to 4600 (2001). Farming has declined: 30 years ago, there exist 900 farmers, by 1981 , the number had dropped to 360 . In 2001, only 230 people participated in farming, just 100 as fulltime farmers. On the contrary the number of employees in the industry and service sectors has grown from 4700 in 1981 to 5800 in $2001.25 \%$ of them commute, attracted by industries in the nearby Rhine Valley. One important business sector is power generation, with 10 hydropower plants in the area, delivering $2500 \mathrm{MW}$ and employing 570 local workers in 2008 . The forestry and lumber industries are also important employers.
The Montafon is a well-established tourist region. In 2001 , tourism provided $26 \%$ of all local jobs, $15 \%$ directly in the accommodation and catering business. Approximately 60 cable cars and ski lifts open up the Alpine terrain for visitors and provide easy access to $220 \mathrm{~km}$ of ski slopes, $100 \mathrm{~km}$ of cross country ski runs and numerous summer hiking routes. In 2001, 940,000 overnight stays were recorded in the valley. This number, however, is considerably below 1.17 million stays, counted in 1981. One reason is the growing accommodation capabilities in the high altitude areas of neighboring municipalities where additional 900,000 stays took place. The proportion of the total overnight stays in private guesthouses has been decreasing since the 1970s, because of the new hotel developments which accommodate a larger share of the growing number of guests. The summer tourist season has lost importance during recent decades. Today, $60 \%$ of tourists visit during the winter.

\section{METHODS: THE PARTICIPATORY APPROACH}

To contact local stakeholders in the study region for launching a participatory process, a close collaboration was established with the "Stand Montafon", a centuries-old organization now working as regional administrative and economic body of all Montafon municipalities. The manager responsible for spatial development and forestry was asked to invite local actors to participate in workshops about sustainable regional development. Most of the inquired stakeholders attended the workshops: farmers, teachers, craftsmen, a retiree, an ecologist, a local planner, a forest expert, a commercial chamber exponent, an artist working part time as skiing instructor. Only two representatives did not attend: a hotel owner and a ski lift company manager. They were possibly concerned about getting involved in discussions dealing with climate change as a threat to tourism, trying to avoid publicity that might diminish the reputation of the area as a winter sports region. The scientists engaged in the case study cover the disciplines of political science, geography and spatial planning, landscape ecology and environmental economics.

Two workshops were held: a scenario workshop and a strategy workshop, one year later. Between the two workshops, a landscape transition simulation 
model was developed to transfer narrative outcomes of the scenario workshop into spatially explicit future landscape scenarios. In the first workshop, twelve local stakeholders took part. Eight participants attended the second workshop.

\section{The scenario workshop}

The purpose of this first workshop was to discuss global change issues at the local scale, with the help of systems analysis and future-scenario building. As start two lectures were held by the scientists, to introduce critical issues of global change, and to create a common understanding of framing conditions and key elements possibly affecting future regional development. One lecture addressed expected climate change effects considering regional climate simulations (Loibl et al. 2007a). The second lecture addressed regional sociodemographic and economic change based on a detailed regional analysis (c.f. Loibl et al. 2008b). Both lectures illustrated that global change is not an issue caused by "the others," related only to climate change or global economic evolution but is also triggered by local behavior.

After the presentations, the twelve local participants split up into three teams according to their main interests: (1) regional economy and tourism, (2) environment and landscape, and (3) society and settlement. After some initial explanations by the scientists, each team carried out a system analysis. The stakeholders identified the critical issues affecting regional development according to their personal focus. To identify the dynamic forces acting upon the regional transition processes, each team developed a visual system model of the region by addressing the important elements and their relationships through causal loop diagrams. Prepared keyword cards, raising issues that influence regional development positively or negatively, guided the participants in the beginning. Empty cards allowed the teams to add issues of their own.

Based on the causal loop diagrams, each team discussed and finally formulated a "wish" scenario and a "threat" scenario of future regional development with respect to global change. Later, these will be called the "positive and negative scenarios." Each team described the changes, advantages and drawbacks of different local aspects. To allow a comparison between the different scenarios, a template was prepared by the scientists addressing the framing conditions and key elements for which advantages and drawbacks should be identified. The details of this template are described in the results section. These pre-defined categories forced the local participants to follow a common structure and to summarize the chances and threats in a concentrated manner.

At the end of the workshop, each team explained its causal loop diagram and presented the scenarios to the other participants. A final discussion, guided by the scientists, revealed a common view of the important issues and their positive and negative local effects. This was the basis for the scientists to derive a summary cause-effect relations diagram, focusing on the critical elements and interrelations that may further change the landscape in this Alpine region.

\section{Scientists' landscape transition simulation}

Between the first and the second workshops, spatially explicit landscape transition simulations were conducted using an agent-based model which delivers regional development alternatives as gridded land use maps of the case study region (c. f. Loibl et al. 2008b). The hypothesis of the model was that certain landscape characteristics elicit certain responses from local actors, resulting in certain migration and cultivation decisions triggering land-use change as can be observed during the last decades by comparing aerial photographs from 1950 and 2005. The transition probability of settlement and forest growth had been explored by spatially relating the observed landscape transition since the 1950s with the neighboring land use class fractions, with elevation ranges and terrain characteristics (c.f. Loibl et al. 2008b). Transition probability surfaces (with 10x 10 $\mathrm{m}$ grid spacing) allow a detailed allocation of land use change based on spatial suitability (for forest growth) or attractiveness (for housing activities) via agents representing new forest patches and households/entrepreneurs occupying new building pots.

The landscape transition model is an adaptation of prior urban growth simulation models, agent based models, which were validated several times for different applications (e.g. Loibl et al. 2003, Loibl et al. 2007b). For the Montafon area the landscape transition model was equipped with additional 
agents, new agent behavior rules. The model was tested through land use change simulations from 1950 to 2005 and was confirmed by comparing model results with observations in 2005. Final landscape transition simulations for 2030 depict the range of possible positive or negative futures shaping the landscape in one or the other direction.

\section{The strategy workshop}

The purpose of the second workshop was to develop strategies to cope with global change by avoiding or mitigating threads described in the negative scenarios and by making use of opportunities addressed in the positive scenarios. The eight workshop participants were split into two teams. Reviewing all diagrams and scenario tables from the first workshop helped the participants to remember the critical issues and to reach a common view regarding which issues released changes of society and landscape in the past and which changes could be expected in the future. To define an effective bundle of local strategies for regional development, the participants were asked to prioritize the most relevant categories listed in the scenario tables that might best control future regional development. Therefore, an interactive weighting task was carried out by the participant teams and also by the scientists' team by applying a spider diagram template. Tourism and its related aspects were identified as promising issues to improve regional development and local strategies were elaborated that should control these issues.

After the workshop, the scientist team distilled the workshop results into generic strategies that were further discussed with a tourism expert whose considerations confirmed the previously formulated strategies and added some new aspects.

\section{WORKSHOP RESULTS}

\section{Scenario workshop results}

The causal loop diagrams drafted during the systems analysis task show significant differences that reflect the roles, interests and knowledge of the contributing stakeholders. The teams' perceptions of positive and negative effects and their importance for regional development resulted in different choices and arrangements of keyword cards to sketch causal loop diagrams (see Fig. 1). Various keyword cards (green) were prepared in advance. Blank cards with different colors could be additionally labeled. The cards' colors were selected by the teams individually to categorize or structure the addressed issues during the diagram drafting process (see Fig. 1). The "society and settlement" team used only a few prepared (green) cards, but added many orange cards appending more detailed aspects. The team addressed social issues and ignored environmental ones. Red cards indicated critical issues that should be improved. The "economy and tourism" team uses many prepared green cards and added some red cards describing impacts of framing conditions and trends. The team concentrated on economic issues and put little emphasis on the environment. The "environment and landscape" team, with members skilled in spatial planning, economy and biology, developed the most elaborated diagram. This team addressed environmental, social and economic issues, indicated the important interrelations and the directions (positive or negative) of the impacts. Many green cards with prepared keywords were used and many additional blank cards were added with their own text. Red cards were selected to emphasize general issues. Orange cards indicated additional important aspects and beige cards marked some strategy targets (see Figure 1 caption). The causal loop sketches did not result in coherent system diagrams but supported the understanding of systems behavior and led to insights about the consequences of future development.

After the workshop, the scientists merged the results of all three teams into one summary cause-effect relationship diagram explaining the landscape transition processes to elaborate some rules for the land use change model (Fig. 2). The most important general driving forces affecting the Montafon society and landscape - climate change, global tourism trends, agricultural markets and subsidy policies - are indicated with diamonds. Rectangles show the system elements - local actors and related pressures - releasing certain responsive behavior. Ellipses show the general impacts on landscape transition. Societal changes were not considered as an external impulse but as an ongoing development within the region.

The explored cause-effect relationships were assumed to release the observed and further expected landscape transformation within the region: 
Fig. 1. The causal loop diagrams indicate clearly the different emphasis of the three teams "Economy and Tourism", "Society and Settlement" and "Environment and Landscape". Green keyword cards were prepared, additional colored cards were added with text prepared by the participant teams. Team one used red cards to represent important issues and orange cards to add more information. Team two selected red cards to emphasize the main cause-effect chains. Team three added red cards to group the green cards and included orange and beige cards for additional details.

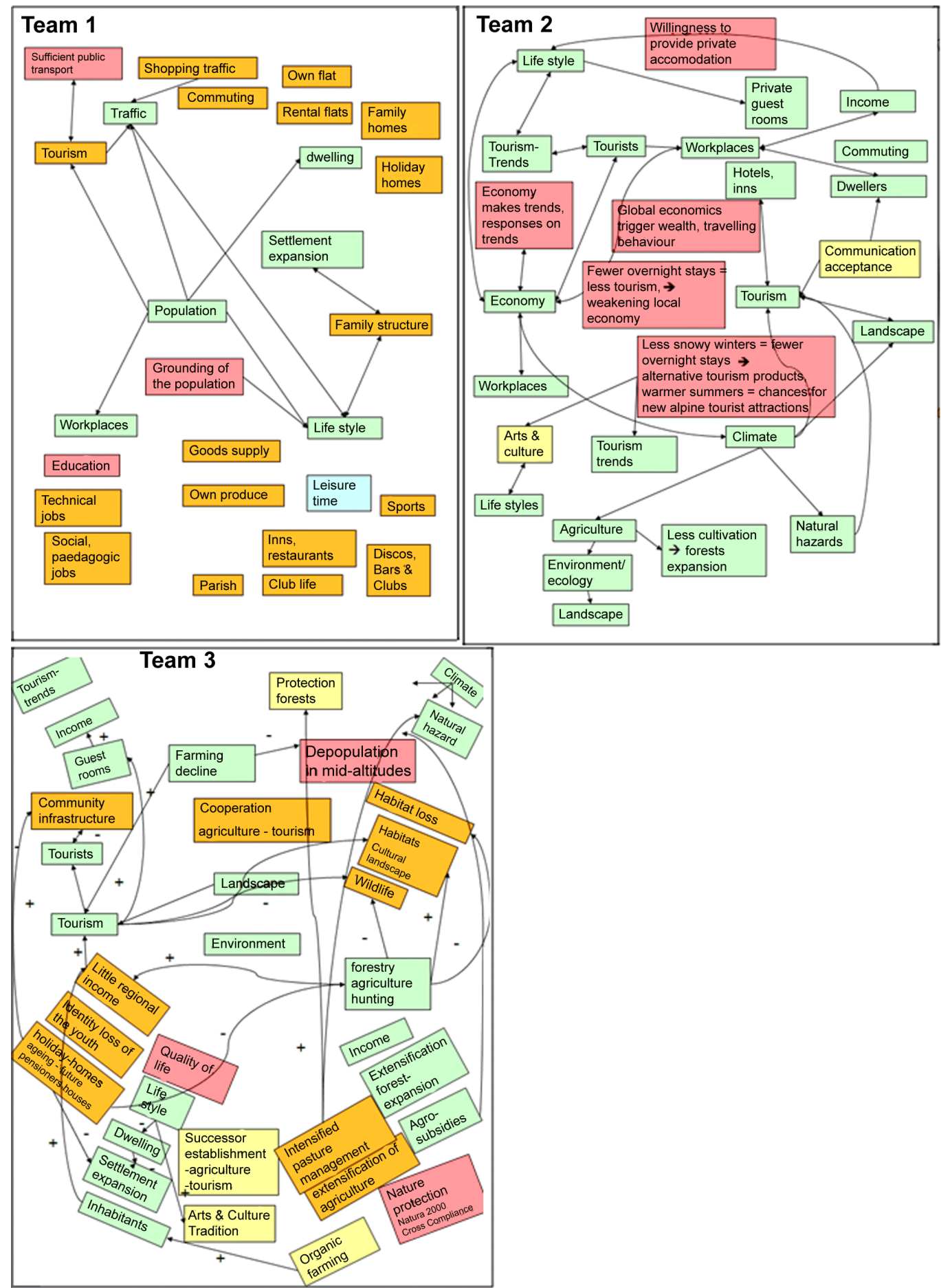


Fig. 2. Cause-effect relations summary diagram focusing on relationships releasing landscape transition. General driving forces affecting society and landscape are indicated with diamonds. Rectangles show the system elements (actors and related pressures) releasing responsive behaviour. Ellipses show general impacts on landscape transition.

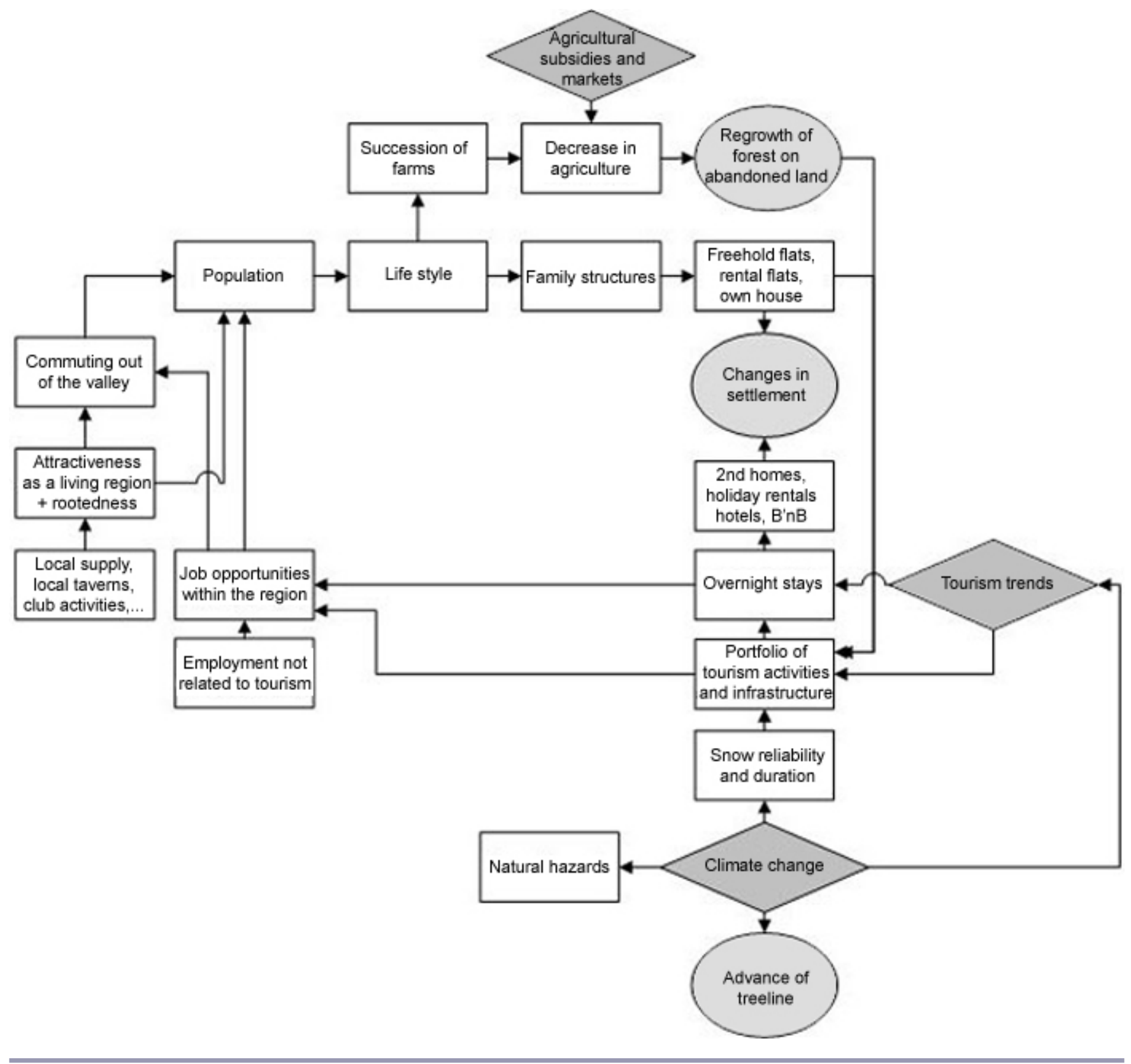


- Settlement expansion is linked with economic and societal changes and lifestyle trends leading to a growing demand for dwelling space per household, a growing demand for larger guest rooms and for more tourist facilities.

- Land abandonment and subsequent forest area expansion is linked with global food market influences and agricultural subsidies, further with farm successor problems and the farmers' desires for more private recreation and leisure time.

- Future upward tree-line shifts will occur in response to climate change (Piotti et al. 2007).

- Those landscape changes may diminish the beauty of the natural scenery and affect the region's attractiveness to tourists when undertaking their various activities.

A table template, addressing farming conditions and key elements causing/affecting local transition, allows a comparison between the scenario pairs of the three teams. The listed farming conditions were listed: climate change, tourism trends and global agricultural economics. The key element list covered population/society, tourism, economy and employment, housing, traffic, agriculture, environment and nature, landscape, arts and culture. (The issues pre-defined by the scientists were "approved" or modified by the local participants: the "arts and culture" key element was additionally requested by the artist participant.) For all categories, future expectations were listed on the table in a narrative way (see Table 1). The positive and negative scenarios of the stakeholder teams spanned the range of future transitions and showed the need for certain development strategies. It was observed that the participants had difficulties in facing negative development and tended towards positive expectations. Some aspects, raised in the positive scenarios, were obviously unrealistic wishes, rather than plausible changes (e.g., still cold, snowy winters and warm, dry summers in the future). Table 1 summarizes the scenario results of the three teams.

\section{Scientists' landscape transition simulation}

The landscape transition simulations are not direct outcomes of the participatory process, but are considered results from the first workshop and supported decision making in the second workshop. The simulation results, conducted as cellular landscapes with $10 \times 10 \mathrm{~m}$ grid spacing, were digitally draped over a digital terrain surface of the Montafon valley, applying a Geographic Information System (Loibl et al. 2008b, Fig. 3). The more realistic 3D-images of the valley allow a better perception of the possible changes in the landscape for the workshop participants.

The images guided the strategy workshop participants after a one-year break, when the land use change model had been developed, again into the research question and made them sensitive to local development effects by spanning the range between a wishful landscape development and a dreadful landscape transition:

1. A moderate settlement growth in the valley floor due to moderate dwelling activities, controlled by zoning restrictions and little further forest expansion because of continuous agricultural cultivation, versus

2. Accelerated settlement expansion in the valley floor and along the neighboring slopes and further large forest expansion released by agricultural extensification and a rising tree line through global warming.

Figure 3 depicts the observed current situation (top) and a hypothetical, less favorable landscape transition in 2030 with accelerated settlement expansion and intensive forest area expansion in all elevation levels (bottom).

\section{Strategy workshop results}

The participants, confronted with the 3Dvisualizations of the possible landscape transformations, were rather impressed by the opposite directions a landscape could evolve as the effect of different strategies. Keeping in mind the discussion results, the issues addressed on the scenario tables were weighted by two participant teams and the scientist team applying spider diagram templates. Initially, while ranking the issues, it was first difficult to distinguish which ones were important and could 
Table 1. Future scenarios for the Montafon region - common positive and negative scenarios extracted from 3 scenario pairs carried out by 3 local stakeholder teams.

\section{Framing conditions}

Climate change Distinctive four-seasons-climate.

Tourism trends

Establishing high quality tourism, culture tourism, and eco-tourism. Acknowledgment of culture and landscape, prioritization on summer tourism, longer tourist stays.

Agricultural policy Continuing of the current agro-subsidizing system. Support of organic farming, subsidizing protection forests, strengthening regional relations and product chains, quality promotion - products \& landscape, promoting sustainability.

\section{Local elements}

Population

Tourism

Economy, workplaces

Settlements

Traffic
Motivation to stay and work in the valley, regeneration of the societal structure, population growth, establishment of two or three generation households, preservation of the village infrastructure with own municipality council and mayor, preschools, schools, local brass band, church choir, fire brigade.

Establishment of a balanced summer and winter tourism. Support of a controlled tourism (walking along trails, nature conservation), appreciation and consumption of local products to gain added value, focus on quality tourism.

The region is established as economic location, diversification increases, small trade businesses and craft businesses are protected, number high quality jobs increases, and number of tourism workplaces is stabilized.

Support of the villages as habitation, village centres are established as centres of local life, terraced housing reduces housing area demand. Main residence status of local inhabitants is preserved, new attractions for youth and families will be established.

Less commuter traffic through new jobs in the valley, local public transport extended, traffic calmed areas erected, cycle path network established, traffic bypass via tunnel.
More extreme weather events, less snow, too wet summers, too dry summers.

Declining quality tourism and increasing mass tourism, establishment of a ,mega party“-image. Declining duration of overnight- stays, growing number of holiday homes.

Mass production - instead of quality production funding, loss of cattle ranching funding leads indoor cattle breeding, zero-grazing and thus less landscape preservation) increase of free competition leads to a decline of small scale farming, genetic engineering endangers organic production habits.

Increased emigration and fewer children leads to aging societies, future multinational immigration (secondary residences, elderly homes, holiday apartments) leads to decline of local resident population, loss of local society cohesion and loss of rural infrastructure demands.

Growing "mega-party"-tourism, declining interest of young local people in tourism business.

Strict profit-oriented development, dependence from single branches, business closure and emigration, big retail chains force small local shops to close.

Settlement expansion by too many single family houses leads to reduction of open space and less social coherence.

Transformation of secondary residences as main residences outnumbers local population.

Loss/reduction of public transport infrastructure, and decline of local job numbers lead to increasing commuting rates and individual transport. 


\begin{abstract}
Agriculture
Preservation of small structured farming and protection of young successors in (secondary occupation) - farming. Farm work is judged as important and attractive.
\end{abstract}

Environment and nature

Landscape

Arts and culture
Conservation of biodiversity and resources provided, no opening of untouched landscapes; environmental awareness in all heads.

Traditional cultural landscape is preserved, scenic landscape is secured.

Encouraging of regional cultural initiatives to establish a rich offering of local cultural amenities. Provision of infrastructure for local cultural events, central culture event marketing. Art and cultural goods are accepted and demanded.
Loss of small-scale farming structure reduces local landscape caring potential. Abandonment of land in middle elevation ranges leads to reforestation:

Landscape patchiness and biological diversity decreases (e.g., rich meadows instead of less fertile grassland), forests expand and reduce open space, resources get lost, opening up of additional pasture areas for skiing.

Forest expansion leads to "dark, monotonous landscapes", removal of landscape elements reduces biodiversity, built-up areas and sealing of land reduces attractiveness of the valley floors.

Cultural identity gets lost: decline of clubs and societies, traditional costume, old knowledge and habits get lost: local identity, local history. be controlled through measures and which ones allowed only little control. In the end, the spider diagrams of all three teams showed high agreement - the shapes of the three small spider webs look rather similar (Fig. 4, left).

To achieve a common view regarding what strategy bundle can effectively control those critical issues that influence regional development most, a consensual weighting task was carried out. This consensual weighting could be easily achieved because of the high similarity of all three spider webs. The large diagram (Fig. 4, right) shows the consensual weighting results. The first three items (in a clockwise direction) in the spider diagram depict the framing conditions of the regional development in this Alpine tourist region, where it was assumed that the agriculture subsidy policy and tourism trends could be controlled to some extent (e.g., through farmer lobbying or provision of touristic opportunities). The key elements "Environment \& Landscape," "Agriculture," "Tourism" and "Regional Economy \& Jobs" showed the highest ratings, expected to be most important for regional development and effectively controllable by local stakeholders. Based on the consensual weighting, the participants decided to concentrate on tourism and closely related aspects - local society, environment and landscape - as the most critical issues.

The local stakeholders' development strategies for the Montafon Region
After an initial discussion about strategies addressing all development issues, the workshop continued with a special focus on tourism, with some attention on related key elements as far as they can be effectively controlled. The most obvious prior transitions with respect to tourism are listed below:

- $\quad$ Some 40 years ago, tourist numbers started to increase and many households built guest rooms to participate in the tourism business and raise their household income. Farmers concentrated on tourist accommodation and worked (part-time) in the local industry; both factors contribute more to the household income than full-time farming.

- The local economy grew as the tourism, construction and logging industries increased. By and by, more people moved into the valley seeking employment opportunities. Farmers recognized the housing area demand and started selling their land. Tourism and population growth led to substantial settlement expansions.

- $\quad$ Since the local population had for decades shared their homes and family life with tourists, the interest of the younger generation in offering private accommodation has appeared to decrease. As overnight stays in private accommodations still add up to a substantial share, the ski lift companies fear 
Fig. 3. Future landscape transition (Top: situation 2005; bottom: dreadful landscape transition 2030 with accelerated settlement expansion and forest area growth, tree-line rise).

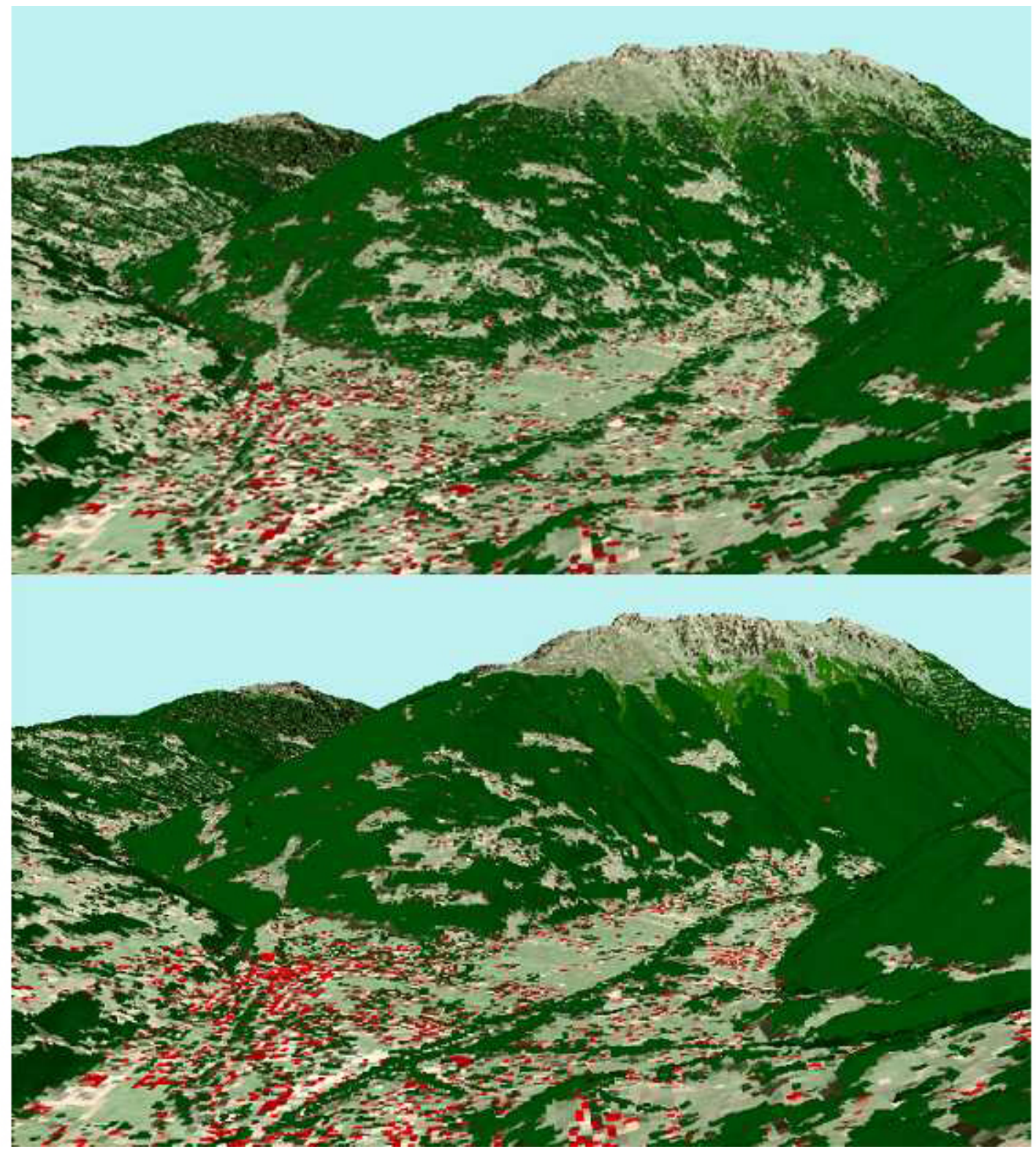

the impact of decreasing guest room capacities on ski lift ticket profits.

- The ski lift companies were for a long time operated by local owners, who were important employers for local workers and customers for local products. With growing numbers of overnight stays and day-trips, the ski lift businesses started growing while maintaining larger skiing areas and demanding more customers to gain higher profits to re-finance the investments. Recently, the largest ski lift company was sold to a bank consortium with less local relations and interests. 
Fig. 4. Weighting of framing conditions and key elements for future development (Left: weightings of the three teams; right: consensual weighting).

\section{Local participant team 1}

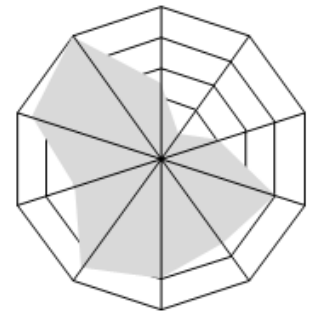

\section{Consensual Weighting}

Local participant team 2

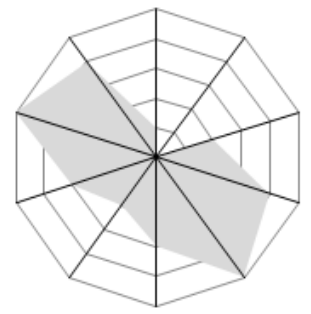

Scientists Team
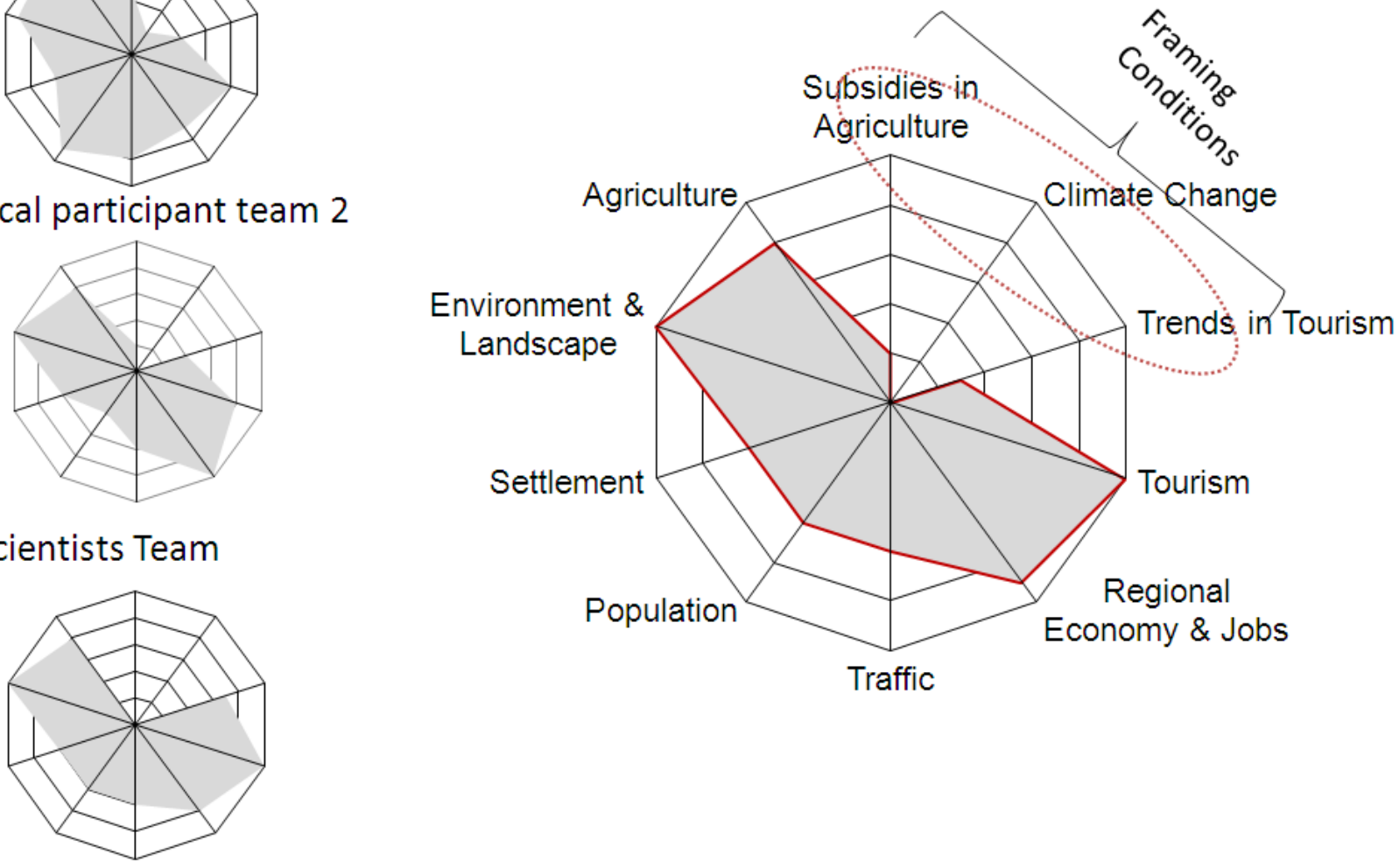

- The increased catering demand appears to be a drawback for local food producers: the growing food demand (for meat and milk) is more recently supplied cheaply by international wholesalers, although local cattle breeding and dairy farming could also deliver (at least for a part of the required supply) better, fresh quality.

- Summer tourism, contributing $40 \%$ of the yearly overnight stays, has substantially less negative side effects. The share of daytrippers is much smaller, and summer tourists contribute more to the local economy because of more overnight stays and local goods and services consumption. The summer activity portfolio, covering sports, nature or cultural issues, is more diverse and more evenly distributed within the area.

For future regional development, certain threats were recognized:

- $\quad$ Scenic areas are in danger of losing multifunctionality and of transforming into a monotonous landscape because of settlement expansion and forest expansion due to less agricultural cultivation.

- Ecosystem services are threatened on the small scale (loss of biodiversity and natural environment) and the large scale (removal of 
mountain headwaters and natural discharge by channeling streams and building dams and reservoirs for extended hydropower production).

- When the number of local people who profit from tourism decreases, the negative side effects of tourism on society and the environment (e.g., more traffic and crowded villages) will be ignored less often.

Three tourism development options within the region were identified: (a) maintaining a wellestablished skiing tourism, (b) supporting a gentle recreation and hiking tourism during the winter and in the summer, or (c) shifting to event tourism.

If tourism remains an important backbone driving the local economy, the selected development option must support a positive cohabitation of the local population and tourists. Thus the common overarching vision was to establish gentle tourism matching the requirements of the local population and in line with the long-term sustainable development of the region.

Four strategies were defined:

One strategy sought to reduce the negative side effects of the accommodation business too much on family life. The reconstruction of high quality guest rooms, separated from the private living area, and the support of hosts with a highly qualified, external workforce would increase guests' and hosts' satisfaction. As the number of private accommodations involving local people may shrink, additional hotel businesses should be established.

The second strategy refers to the decreasing reliability of snow due to climate change. To reduce the dependence of winter tourism on snow cover, a transition from a "skiing holiday"-focus to more diverse "winter holidays", including a controlled shrinking of the skiing tourism, will be released. Therefore, a diversification of the activity options is necessary to be carried out in collaboration with the ski lift companies.

The third strategy underscores the increasing potential for summer tourism under climate change. With an already diverse portfolio of summer activities and rising summer temperatures in adjacent lowland areas, the Montafon region could extend the summer season to early autumn and late spring.
The fourth strategy will support the eco-friendly state and the branding of the region, its resources and products. The attractiveness for leisure activities in the summer and winter will improve, making use of the valley's nature and culture.

\section{GENERIC VISIONS AND STRATEGIES FOR ALPINE TOURIST REGIONS, DERIVED FROM LOCAL DECISIONS}

Grounded on the strategy discussions of the local stakeholders and the further consultation of tourism experts, a generic vision for the Alpine regions has been formulated by the authors. Against the global trends towards highly specialized, investment intense and internationally competing winter sport resorts, this vision aims for maintaining a diverse economy in wealthy valleys with local goods and services addressing the locals, as well as day trippers and tourists. To achieve such an ideal goal, generic strategies should be implemented for many Alpine tourist regions, but without specifying a narrow corset of measures that must be defined with respect to the local resources and interests.

The following generic strategies for Alpine tourist regions, interconnected with each other, could be adopted:

1. "Gentle tourism:" Establishing a high quality, gentle tourism that contributes sufficiently to regional income through the provision of high quality tourist accommodations that allow local people substantial income and ensure the guests' satisfaction. Holiday activities will match the needs of tourists, making use of local resources, giving opportunities for outdoor adventure and improving personal wellness and health at all ages. These activities will involve local people as instructors or participants and provide new local jobs and local income by giving attention to guests.

2. "Smart shrinking:" To reduce the risk of decreasing snow reliability due to climate change, the shrinking of skiing tourism should be treated as a chance event, shifting the focus from "skiing holidays" to the more diverse "winter holidays." Therefore, a diversification of the activity options, in collaboration with the ski lift companies, is necessary. Skiing should retreat to reliable snow areas. Rationing of one-day skiing 
passes may help to control access to limited capacities if necessary.

3. "Cool mountains:" To benefit from climate change, high altitude areas can serve as cool retreats for the urban population wanting to escape hot summer cities or sticky Mediterranean coasts. Warm spring and mild autumn weeks could help extend the Alpine summer season and shorten off-season periods. Traditional maintenance of Alpine landscape and appropriate infrastructure and activity offers (e.g., swimming, guided rafting, paragliding, hiking, climbing tours, musical education seminars, arts-and-crafts courses, and mental relaxation training) will enhance the Alpine resorts' attraction and provide opportunities for meaningful activities and the establishment of social contacts for the young and singles as well as for active elderly people.

4. "Eco-region valleys:" The region will be transformed to achieve an eco-friendly state, and the branding, products and services of the region will be improved. Part of this strategy is the continuous cultivation of the landscape through small-scale farming and better integration of local production in local goods supply chains, advocating a more selfsufficient regional economy. Tourists should also be encouraged to buy local goods and retailers should be encouraged to order food from local sources instead of from remote markets.

Combining tangible goods and services with intangible ones found in the mountain areas - rural lifestyle and tradition, nature conservation and ecological niches, landscape scenery and opportunities for outdoor activities - may help those regions to gain competitive advantages. Without exposing themselves to high risk investments with regard to international trends and competition in tourism and climate change, these strategies might support the long-term sustainable development of many mountain tourist regions.

Table 2 lists the derived strategies for the sustainable development for Alpine tourist regions, concentrating on tourism, but also mentioning further aspects that are not presented here in detail because of limited space.

\section{DISCUSSION}

\section{Workshop setting}

The integration of stakeholders for scenario building and strategy development allows the identification of the most critical issues of global change and their impacts from a local perspective. It is important that discussions not be cut short, as they reveal much of the participants' local knowledge, exploring the relevant issues and reducing the uncertainty in developing strategies and providing an information exchange between the stakeholders.

From an abstract level of "systems, elements, causes and effects," the local example tied the stakeholders to their "real world" and unfolded the complexity of regional transition processes. After some general discussion about future development, the stakeholders identified the key issues to enhance local economic development and landscape transition. The intensive discussions allowed judging the stakeholders' views as "local" or general, applicable either for the very local case or - with some adaptation - for many Alpine tourist regions. The prepared 3D-images illustrated possible landscape changes and served as a warning to avoid uncontrolled land cover transition, supporting the willingness to carry out strategies that may lead to drawbacks in the near future but will improve long-term regional development.

\section{Global change and local mitigation strategies}

The starting point of the participatory collaboration was to cope with global change, comprising economic, societal and climate change, and their effects on the local society and landscape. During the participatory process, some selected aspects of global change dominated the discussion, while others were neglected, despite their importance for the region. Climate change resulting in less snow reliability was not considered as an urgent issue by the local stakeholders. Subsidy policies protecting local agriculture developed to a major point of discussion, and the role of agriculture as a cultural backbone and an instrument that shapes the landscape and preserves its attractiveness was recognized. Tourism was a matter of intense discussion, according to its potential to disturb private life, the regional environment (e.g., through the increase of traffic). Finally, though, it was 
Table 2. Generic strategies for Alpine tourist regions derived from strategy discussions with local stakeholders.

\section{Framing conditions}

Climate change

Tourism trends

Economy, Agricultural policy

\section{Local elements}

Population

Tourism

Economy, workplaces

Settlement, infrastructure

Agriculture and forestry

Traffic

Environment \& nature

Education \& culture

\section{Adaptation \& mitigation strategies for alpine tourist regions}

Cultivate high altitude summer pastures for cattle grazing to hinder timber line rising. Adaptation of settlement structure to cope with natural hazards trough climate change.

Offer quality tourism with regional identity, brand development! Winter tourism - adaption of the touristic usage on changing climate conditions: smart shrinking.

Coping with globalized markets, reorientation of agricultural production towards local, high quality products not dependent on global agro-market trends and subsidies

\section{Development strategies for alpine tourist regions}

Supporting local identity, attracting population to stay and grow.

Growth of nature oriented tourism, increased summer offerings, smart shrinking-concepts for winter tourism. Cooperation of municipalities and ski lift companies, mutual investment decisions and sharing on the receipts.

Using local resources for goods production with higher value instead of low value goods "export", improving worker qualifications, providing new jobs by establishing whole year tourism and company founding.

New housing shall be concentrated within the current the settlement borders, renovation of old houses instead of building new ones, provision of flats for young families, limited holiday home numbers.

Selective fallow land management, well-adapted biomass usage as raw material for higher value goods production and as energy source, strengthening/expansion of regional brands, agricultural products.

Traffic-decreasing regional planning measures, establishment of an attractive public transport pricing structure and offer of jobs in traffic business.

Support of landscape care measures by farmers, strengthening environmental awareness in all heads.

Infrastructure for cultural events, central bureau for cultural event marketing, encouragement of regional cultural initiatives. considered as a remarkable source of income and the most promising point of local action.

\section{Stakeholders' perspective: the local uniqueness and transferability of strategies}

Local stakeholders often consider their region highly unique. But many issues occur also in other Alpine tourist areas: motorways connect densely populated areas with the Alpine hinterland, increasing Alpine tourism business and releasing larger day-tripping numbers instead of overnight stays. Settlements expand through the construction of new tourist accommodations, infrastructure and holiday homes. Agriculture declines because of new income opportunities, resulting in landscape change. All of these factors diminish local attractiveness. Tourism fatigue evolved because of growing tourist crowds, growing traffic, disturbing the environment and local society. 
A few issues in the Montafon valley are different from other Alpine areas: (1) many close hydropower plants drive the local population to prevent additional hydropower plants and high-voltage power lines, distressing the regional landscape and ecology, (2) there is a private railway, providing convenient public transport to the Rhine valley, (3) there is the "Maisäss" landscape, where a threeelevation-level grazing culture transformed former forested slopes in the mid-altitudes into pastures, which are used to feed livestock during spring and autumn until (and as long) the high altitude pastures are free of snow. The decline of sheep and cattle breeding endangers grazing land slopes to be reforested.

Despite these unique aspects, the addressed regional problems refer to globally induced changes and are relatively common. But as global change effects are observed locally, strategies are planned with respect to local advantages, which may lead to cross-scale conflicts. Local strategies may disturb neighboring regions or affect superior scales, while superior level strategies may disadvantage local scales. Sufficient solutions for different spatial scales are difficult to find in a local stakeholder process. Scientists should not be relied upon to speak for other regions or scales, as a certain degree of mutual trust is the crucial basis of transdisciplinary collaboration. To keep this reliance alive, scientists are not recommended to suggest or defend decisions that support the interests of other regions conflicting with the interests of the region at hand.

To avoid such disadvantages, a more complex participatory approach has to be carried out that includes stakeholders representing not only different interest groups but also different regions and spatial scales (as suggested by Kok et al. 2006 and Biggs et al. 2007).

\section{CONCLUSION}

The participatory process to develop general visions and strategies for a region to cope with global change impacts has proved quite successful. System analysis approaches introduce system thinking and a common view about critical issues and connected cause-effect relations. The development of a "wish"- and a "thread"-scenario identified the critical transition trajectories and key elements that might trigger these transitions. Ranking the most critical issues allow to focus on strategies that can effectively influence future development. Although developed for one region, the identified strategies were considered suitable as a basis of inspiration for strategy development in many similar Alpine tourist areas. Solving cross-regional or multi-scale conflicts with participatory approaches might require a detailed mediation process, in which stakeholders of all involved spatial scales should be integrated.

Responses to this article can be read online at:

http://www.ecologyandsociety.org/voll5/iss3/art3/responses/

\section{Acknowledgments:}

We thank our local partners for their dedication, first of all Bernhard Maier from the "Stand Montafon" who facilitate the stakeholder collaboration. Furthermore we would like to thank the "proVision" program coordinators from the Austrian Federal Ministry of Science and Research $(B M W F)$ for funding the project "future.scapes " which this article refers to.

\section{LITERATURE CITED}

Biggs, R., C. Raudsepp-Hearne, C. AtkinsonPalombo, E. Bohensky, E. Boyd, G. Cundill, H. Fox, S. Ingram, K. Kok, S. Spehar, M. Tengo, D. Timmer, and M. Zurek. 2007. Linking futures across scales: a dialog on multiscale scenarios. Ecology and Society 12(1):17. [online] URL: http:/ /www.ecologyandsociety.org/vol12/iss 1/art17/

Brundtland, G. H., and The World Commission on Environment and Development (WCED). 1987. Our common future. Oxford University Press , Oxford, UK.

Klein, J. T., W. Grossenbacher-Mansuy, R. Häberli, A. Bill, R. W. Scholz, and M. Welti, editors. 2001. Transdisciplinarity: joint problemsolving among science, technology and society. An effective way of managing complexity. Birkhauser Verlag, Basel, Switzerland.

Kok, K., M. Patel, D. S. Rothman, and G. Quaranta. 2006. Multi-scale narratives from an IA perspective: part II. Participatory local scenario 
development. Futures 38(3):285-311.

Loibl, C. 2002. Aber was bitte ist Transdings...? Kontexte 2:6-7.

Loibl, W., and T. Tötzer. 2003. Modeling growth and densification processes in sub-urban regions simulation of landscape transition with spatial agents. Environmental Modelling and Software 18 (6): 485-593.

Loibl, W., A. Beck, M. Dorninger, H. Formayer, A. Gobiet, and W. Schöner. 2007a. Research for climate protection: model run evaluation (reclip: more), project summary report. Austrian Research Centers Systems Research (ARC-sys), Wien, Austria. [online] URL: http://systemsresearch.arcs. ac.at/SE/projects/reclip/climate change scenarios. pdf

Loibl, W., T. Tötzer, M. Köstl, and K. Steinnocher. 2007b. Simulation of polycentric urban growth dynamics through agents - model concept, application, results and validation. Pages 219-235 in E. Koomen, J. Stillwell, A. Bakema, and $\mathrm{H}$. Scholten, editors. Modelling land-use change progress and applications. Springer, Dortrecht, Netherlands.

Loibl, W., I. Darnhofer, T. Tötzer, M. Knoflacher, A. Walz, S. Sedlacek, C. Loibl, S. Edegger, E. Gebetsroither, and A. Sonntag. 2008a. future. scapes. Globaler wandel und seine auswirkungen auf landschaft und gesellschaft. Szenarien künftiger entwicklung und lösungsstrategien zur minderung negativer effekte - Synthesebericht. Austrian Research Centers GmbH (ARC), Systems Research, Vienna, Austria.

Loibl, W., A. Walz and E. Gebetsroither. $2008 b$. future.scapes. Teil 3, projektteil-mountain.scapes: Bericht 2 - Szenarien künftiger entwicklungen und strategien für eine nachhaltige entwicklung im Montafon, quantitative simulation der veränderung der landschaft. Austrian Research Centers GmbH (ARC), Systems Research, Vienna, Austria.

Loukopoulos, P., and R. W. Scholz. 2004. Sustainable future urban mobility: using 'area development negotiations' for scenario assessment and participatory strategic planning. Environment and Planning A 3612:2203-2226.
Lundström, C., S. Kytzia , A. Walz, A. GrêtRegamey, and P. Bebi. 2007. Linking models of land use, resources, and economy to simulate the development of mountain regions (ALPSCAPE). Environmental Management 40(3):379-393.

Piotti, A., P. Piovani, M. Scalfi, S. Leonardi, and P. Menozzi. 2007. Global change and upward shift of treeline in the Alps: genetic consequences of pastures colonization.Forest@ 4(1):69-78. [online] URL: http://www.sisef.it/forest@/show.php?id=431

Scholz, R. W., and O. Tietje. 2002. Embedded case study methods - integrating quantitative and qualitative knowledge. Sage Publications, Thousand Oaks, California, USA.

Scholz, R. W., D. J. Lang, A. Wiek, A. Walter, and M. Stauffacher. 2005. Transdisciplinary case studies as a means of sustainability learning: historical framework and theory. Working Paper 43. Zürich. Switzerland. [online] URL: http://www. uns.ethz.ch/people/hs/scholzr/publ/res reports/UNS A129. pdf

Tötzer, T., W. Loibl, and S. Sedlacek. 2007. From global pressures to local strategies: How can transdisciplinary research contribute to building more sustainable regions? Pages 336-337. Proceedings of the 47th Congress of the European Regional Science Association - local governance and sustainable development, 29 August - 2 September, 2007, Paris, France.

van Notten, P. W. F., J. Rotmans, M. B. A. van Asselt, and D. S. Rothman. 2003. An updated scenario typology. Futures 35:423-443.

Walz,A., C. Lardelli, H. Behrendt, C. Lundstöm, A. Grêt-Regamey, S. Kytzia and P. Bebi. 2007. Participatory scenario analysis for integrated regional modelling. Landscape and Urban Planning 81:114-131. 